\section{Volume $4 \cdot$ Nomor $1 \cdot$ Oktober 2020 \\ Pege (Hal.) : 93 - 101}

(C) Universitas Pamulang

JL.Surya Kencana No.1 Pamulang, Tangerang Selatan - Banten Telp. (021) 7412566, Fax (021) 7412491

website. :

http://www.openjournal.unpam.ac.id/index.php/JPK

\title{
Desain dan Pengembangan dalam Meningkatkan Citra Pasar Tradisional di Era Disrupsi pada Kota Tangerang Selatan
}

\author{
Fahmi Susanti ${ }^{1}$; Derizka Inva Jaswita ${ }^{2}$ \\ Universitas Pamulang e-mail : dosen02024@unpam.ac.id
}

\begin{abstract}
Abstrak. Tujuan penelitian untuk menganalisis formasi serta pengembangan pasar tradisional pada kota Tangerang Selatan. Objek yang diteliti ialah empat pasar tradisional di kota ini. Metode penelitian yang dipakai kombinasi methode. Teknik pengumpulan data tanyajawab narasumber ,serta pemantauan area secara langsung. Metode analisis data 1)validasi konstruk yaitu triangulasi sumber serta triangulasi metode 2)analisisSWOT.Hasil menunjukkan : belum dilakukannya pengembangan pasar tradisional di kota Tangerang Selatan belum sesuai Perpres No 112 tahun 2007. Dapat disimpulkan bahwa tatanan serta pengembangan representasi pasar tradisional belum diupayakan semaksimalnya sehingga citranya masih dipandang sebelah mata.
\end{abstract}

Kata kunci: IFAS; pengembangan; pasar tradisional;SWOT

Abstract. The research objective is to analyze the formation and development of traditional markets in the city of South Tangerang. The object under study is four traditional markets in this city. The method used is combine method. Data collection techniques by interviewing key information and observing directly on the area under study. Data analysis methods are: 1. Construct Validation, the source triangulation and triangulation method, 2. SWOT Analysis. The results showed:the development of traditional markets in South Tangerang city was not yet in accordance with Presidental Regulation No. 112 of 2007.It could be concluded that the order and development of traditional market represent had not been maximally pursued so that its image was still underestimated.

Keywords: development ;IFAS; SWOT; traditional market 


\section{A. PENDAHULUAN}

Adanya pasar tradisional selaku sentral kegiatan ekonomi rakyat dari golongan rendah mencapai pelaku usaha siap melancarkan negoisasi jual beli. Tapi, bersamaan dengan berjalannya zaman, muncul pasar modern seperti supermarket dan minimarket datang memojokan pasar tradisional dari distrik metropolitan mencapai pelosok dusun. Seiring dengan perkembangan usaha di Indonesia, tempat berbelanja saat ini sangat dibutuhkan masyarakat. Usaha timbul akibat keinginan halayak untuk berbelanja keperluannya semakin membesar.. Adanya ketertarikan konsumen yang sangat besar pada pasar ini membuat banyak usahawan berlomba lomba untuk melakukan inovasi pelayanannya.

Pasar modern menjadi daya tarik warga sebab reduksi harga komoditi yang mereka jajakan bervariasi,komplet dan bermutu ketimbang pasar tradisional serta pelayanannya baik dan cepat. Ini menciptakan problematik yang mengintimidasi pasar tradisional di kelompok publik, dari segi pasilitas,pasar tradisional acap terkucilkan lewat kritikan lokasinnya yang kotor,becek,bau yang dijadikan dalih ketidaknyamanan dan rasa aman khalayak saat belanja. Berdasar "Peraturan presiden No 112 th 2007 "Penataan dan Pembinaan Sarana Distribusi Bidang Perdagangan,Pusat Perbelanjaan dan Toko Modern."Menjadi salah satu kota penyangga Ibukota yang memiliki kepadat an penduduk cukup besar memicu sorotan pada pemerintah kota tangerang selatan, yang paling tertentang yaitu pada pasar tradisional di area tersebut yang perlu aksi pemerintah untuk segera diperbaharui. Diantaranya ada pasar ciputat,pasar jombang,pasar bintaro sector dan pasar serpong yang belum sesuai dengan "Perpres No 112 th 2007". Beberapa factor problema yang menjadi belum majunya pasar tradisional diantaranya : lemahnya tatalaksana pasar,minimnya atensi akan layanan saluran pembuangan air serta wadah penyingkiran limbah dan tidak tersedianya lahan parker yang layak. Hal ini menimbulkan potret negatif pada pasar tradisional, data "kemendagri.go.id pertumbuhan pasar tradisional di Indonesia setiap tahunnya mengalami kemunduran yang cukup substansial mulai dari th (2007) 13.550 unit, th (2009) 13.450 unit, (2011) 9.950 unit, (2013) 9.850 unit, (2015) 9.769 unit, (2017) 9.550 unit.

Pemerintah kota Tangerang selatan wajib bekontribusi memecahkan urusan ini agar cepat terdeteksi solusinya.Tindakan untuk tetap stand up serta menjamin ketersediaan pasokan komoditas kebutuhan pokok bagi rakyat yaitu dengan merancang ulang, melancarkan pengembangan serta potret pasar tradisional supaya makin memuncak apalagi di era serba canggih seperti ini, cara tersebut bisa membantu menyaingi pasar modern agar pasar tradisional bisa terus beroperasi dan bercitra positip. Proses renovasi dimulai dengan memperbaiki tata ruang pasar untuk melelapkan label pasar kotor,bau,becek yang melekat pada pasar tradisional,pengelolaan sumber daya manusia lebih dimaksimalkan lagi,memperbaiki bobot layanan serta merencanakan sistem pembayaran mengikuti kemajuan ilmu ,misi utama renovasi tersebut untuk mengharumkan label pasar tradisional akan komentar positif seperti dukungan dan pujian. Agar atensi khalayak modern balik berbelanja ke pasar tradisional dan pasar tradisional secara alami berkesinambungan menjadi titik kegiatan ekonomi rakyat.

Pemerintah pasar tradisonal pada kota Tangerang Selatan khusunya dibeberapa kecamatannya yaitu pasar Serpong,Ciputat, Bintaro,sector 2, Jombang ditemukan perkara rancangan komposisi gedung yang tatananya belum rapi,serta masih semrawut dan kumuh,representasi potret pasar tradisional negative,teknik promo serta mendagangkan jualannya belum singkron dengan kesuksesan rekognisi,didapat data mundur dan lesunya pasar tradisional. Merujuk keadaan ini peneliti mempunyai ketertarikan untuk melangsungkan reseach bertema desain dan pengenbangan dalam meningkantkan citra pasar tradisional di era distrubsi pada Kota Tangerang Selatan 
Perumusan masalah: bagaimanakah pengimplementasian peraturan pemerintah terkait penataan pasar tradisional kota tangerang selatan? bagaimanakah penataan komposisi fisik pasar tradisional pada kota tangerang selatan? bagaimanakah pengelolaan pemberdayaan penjaja dalam menyesuaikan diri dengan majunya zaman

Tujuan penelitian ini ialah untuk mengetahui serta menganalisa secara deskriptif penataan komposisi fisik pasar tradisional pada Kota Tangerang Selatan untuk mengetahui serta menganalisis secara deskriptif pengelolaan pemberdayaan penjaja dalam menyesuaikan diri dengan majunya jaman pada pasar tradisional kota tangerang selatan.

\section{B. KAJIAN LITERATUR}

\section{Manajemen Sumber Daya Manusia}

lalah rangkaian upaya penyesuaian diri dengan pengembangan yang tanpa batas,un tuk menekan pemborosan,karena diterapkan sikap teliti serta sikap cermat, bekerja meraih sasaran bersama,maka diperlukan item item proses yang memerhatikan pada kebijakan merencanakan,mengorganisasikan serta pengontrolan. Maka manajemen sumber daya manusia sangat berguana membantu memberi keseluruhan gambaran dari pengambilan akhir keputusan strategis. Konsep "Malayu S.P Hasibuan (2012:9)"

\section{Desain dan Pengembangan}

Bisa dikatakan sebagai suatu cara atau kegiatan yang mengatur semua hal atau objek sebelum dilakukannya tindakan. dalam proses rancangan ruang, amat memperkirakan segala aspek mulai dari nilai estetika, fungsi dan aspek lainnya yang didapat dari gagasan khalayak (sachari,2000). Maka dari itu desain pengembangan mempunyai tujuan serta fungsinya sendiri sebagai perangkat pendukung tahap merealisasikan objek baru serta alat penyampaian idea atau konsep sebagai wadah untuk memaparkan objek spesial kepada publik dengan kondisi actual. Untuk tujuan dapat meningkatkan keefisiensian, produkvitas dan meningkatnya pendapatan khalayak, sedangkan "pengembangan" adalah suatu proses, tindakan yang tumbuh secara teratur untuk memanisfestasikan suatu perubahan agar menjadi makin rapi lagi untuk kedepannya,yaitu untuk menaikan kemampuan, idea, konsepsi sesuai kepentingan .

\section{Citra}

Berupa impresi atau gambaran yang timbul secara alamiah dalam hati nurani berdasarkan tanggapan,, apresiasi akan suatu pengamatan. Suatu yang biasa dijadikan bahan tanggapan bisa berwujud suatu karya, kegiatan ataupun pada sebuah sasaran yang telah ditentukan (Linggar, 2000) Terdapat dua jenis tanggapan yang biasa diberikan kritisi ada sifatnya positif, berupa dukungan dan pujian oleh halayak terhadap suatu karya atau kegiatan dan tanggapan negatip yang berisi sebuah penolakan, dan menimbulkan kesan pertentangan. Maka citra pada pasar adalah tolak ukur kepuasan halayak yang bisa terungkap lewat opini, memori, atau responsi. Setiap insan mampu melihat label suatu objek berbeda-beda, tergantung pada pendapat dirinya mengenai objeknya. Label ini dibangun berdasarkan orienntasi terhadap keuntungan yang diingini sesuai keperluan. 


\section{METODOLOGI PENELITIAN}

\section{Lokasi dan Waktu}

Objek di 4 Pasar Tradisional Kota Tangerang Selatan Pasar Serpong, Ciputat, Sektor 2 Bintaro, Jombang. Ini dilaksanakan selama enam bulan.

\section{Metodologi Penelitian}

Yaitu pendekatan kombinasi method, yaitu teknik triangulasi serta analisis SWOT.Dimana bahan yang didapatkan akan dipelajari lebih jauh dan dalam lagi, lalu akan dituangkan dalam bentuk cerita narasi serta digit. Metode ini dipakai untuk menggali / menyelami serta mengkaji perkara yang ada lalu akan memberikan formulasi strategi yang dinilai lebih baik dan lebih taktis dalam upaya pengembangan serta tumbuhnya pasar. Hasil dari rangkaian analisa ini akan memberikan suatu pertimbangan alternatip.

\section{Populasi serta Sampel}

Teknik purposive sampling ialah untuk menetapkan informan. Sampel yaitu kepala "Disperindag Tangerang Selatan", penjaga pasar, pengelola pasar, serta pembeli. Populasi ialah penjaja dan pembeli di 4 pasar tradisional ini.

\section{Teknik Penentuan Data}

Terdiri : data sekunder serta data primer

\section{Metode Analisis Data}

Metode di Penelitian ini ialah 1) Validasi Konstruk dengan tujuan terjaminnya sahihnya data yang didapatkan, disini penelitian memakai Teknik triagulasi. ialah proses untuk pemeriksaan kebenaran suatu barang dengan menggunakan perbandingan dengan bahan yang didapatkan dari sumber- sumber lainnya, baik saat tahapan penelitian di lapangan, serta pada saat yang berlainan "(Nasution, 2003 :115)." Teknik yang dipakai yaitu, "Triagulasi sumber" dan "Trigulasi metode".a) Trigulasi Sumber artinya ialah peneliti melakukan perbandingan dan melakukan pemveritikasian posisi. Kepercayaannya sesuatu penginformasian yang dibapatkan dengan Teknik waktu dan Teknik alat yang keseluruhannya berada di penelitian kualitatip, kesimpulan dari ("Patton dalam Meleong, 2006 : 330"). b) Triagulasi Metode ada dua strategi ialah dilakukan pengecekan derajat posisi saat pengumpulan bahan, pengecekan dari posisi kepercayaan dari beberapa sumber didapatkannya bahan dengan menggunakan pola yang sama. Memakai teknik ini maka akan dipastikan hasil penelitian yang benar- benar hasilnya bisa dpercaya. Secara metodologi bisa didapatkan. Kesimpulan dari ("patton dalam meleong 2006 : 331"). 2.)Analisis SWOT. Teknik Triangulasi tersebut kemudian dipadukan, diteruskan "matriks IFAS EFAS" dengan tujuannya mengukur teknik apa yang sesuai diterrapkan agar lebih produktip, serta berharap menghasilkan dan menerapkan rancangan strategi lebih tepat. Selanjutnya akan dibuat formulasi strategi yang dinilai lebih baik dan lebih taktis dalam upaya pengembangan serta tumbuhnya pasar. Hasil dari rangkaian ini akan memberikan rekomedasi alternatip 


\section{HASIL DAN PEMBAHASAN}

Kekuatan Internal: Lokasi strategis, umumnya dekat dengan pasilitas kesehatan.,tersedia keperluan keseharian yang lengkap,hHarga merakyat.B) Faktor kelemahan internal: Banyaknya pedagang kaki lima membuat macet, semrawut.,tidak adanya pembaruan di pasar hingga untuk komoditas serta layanan cenderung ketinggalan jaman.sangat terikat kebiasaan menawar sehingga sulit untuk berubah, terlalu padat, kurang baiknya Pengelolaan sampah, banyaknya pungli, kisaran 50.000/hari, jalanan becek, aroma bau pasar tidak enak asalnya dari sampah, lahan parkiran kurang lebar, angkatan umum parkir sembarangan.C) Faktor peluang : Teraturnya pembagian lapak penjaja sesuai barang yang di perjual belikan hinga pembeli tidak lagi kebingungan dalam mencari barang, sampah/limbah bisa dijadikan pupuk, sampah nonorganik bisa dijadikan kerajinan tangan serta membuka lapangan kerjaan baru bagi hal layak, pasar menjadi pusat grosiran bagi penjaja eceran, adanya campur tangan pemerintah atau pihak swasta dalam mengembagkan pasar ini, aihak pasar bisa bekerja sama dengan halayak untuk menambah parkiran. .D) Faktor ancaman : Perkembangan teknologi yang cepat membuat pasartradisional jauh tertinggal contoh dalam proses transaksi yang harus menggunakan uang cash, maraknya pasar modern dengan posisinya berdekatan, sehingga terjadi saingan yang terkadang melemahkan pasar tradisional,terkoordinirnya Kebersihan membuat pasar modern lebih nyaman ,teknik pemasaran pasar modern seperti membuat promo, potongan harga.

(Tabel 1. Matriks Penilaian SWOT tabel IFAS EFAS)

\begin{tabular}{|c|c|c|c|c|}
\hline & 'Faktor & "Integrity" & "Rating" & "Score" \\
\hline \multicolumn{5}{|c|}{ “IFAS STRENGTH” } \\
\hline 1 & Mudah dijangkau & 0,08 & 4 & 0,32 \\
\hline 2 & Harga merakyat & 0,15 & 4 & 0,6 \\
\hline 3 & Tawar menawar & 0,17 & 4 & 0,68 \\
\hline 4 & Dekat "pusat bisnis \& pendidikan" & 0,06 & 4 & 0,24 \\
\hline & & & & 1,84 \\
\hline \multicolumn{5}{|c|}{ "IFAS WEAKNESS" } \\
\hline 1 & Sistem drainase & 0,06 & 2 & 0,12 \\
\hline 2 & Lalu lintas sekitar & 0,15 & 3 & 0,45 \\
\hline 3 & Pungutanliar & 0,06 & 3 & 0,18 \\
\hline 4 & Parkir sempit & 0,06 & 2 & 0,12 \\
\hline 5 & Penjaga keamanan & 0,06 & 3 & 0,18 \\
\hline 6 & Banyak PKL & 0,15 & 2 & 0,30 \\
\hline
\end{tabular}


ISSN NO. (PRINT) 2598-0823, (ONLINE) 2598-2893

\begin{tabular}{|c|c|c|c|}
\hline & 1,0 & & 1,35 \\
Total & & & 3.19 \\
\hline
\end{tabular}

\begin{tabular}{|c|c|c|c|c|}
\hline \multicolumn{5}{|c|}{$\begin{array}{c}\text { "EFAS } \\
\text { OPPORTUNITIES" }\end{array}$} \\
\hline 1 & Pusat Grosir & 0,05 & 4 & 0,2 \\
\hline 2 & Peremajaan pasar & 0,1 & 2 & 0,2 \\
\hline 3 & Demografi & 0,15 & 4 & 0,6 \\
\hline 4 & SuportPEMDA & 0,1 & 3 & 0,3 \\
\hline 5 & Modernisasipembayaran & 0,1 & 2 & 0,2 \\
\hline & & & & 1,5 \\
\hline \multicolumn{5}{|c|}{ “EFAS THREAT” } \\
\hline 1 & "Pasar modern" & 0,1 & 4 & 0,4 \\
\hline 2 & Beubahnya gayahidup & 0,1 & 4 & 0,4 \\
\hline 3 & Berubah tataruang & 0,1 & 3 & 0,3 \\
\hline 4 & Pungli & 0,1 & 3 & 0,3 \\
\hline 5 & koordinasi akankeamanan & 0,1 & 2 & 0,2 \\
\hline \multicolumn{2}{|r|}{ Total } & 1 & & $\begin{array}{l}1,6 \\
3,1\end{array}$ \\
\hline
\end{tabular}

Sumber: Hasil olah data (2020) 


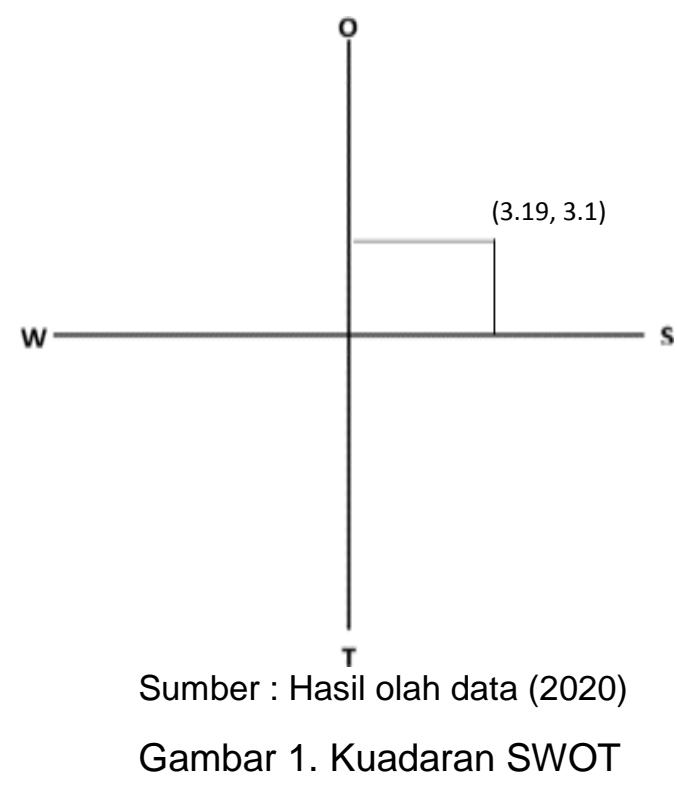

Setelah dilakukan analisis SWOT maka didapatkan pasar Ciputat, pasar Jombang, pasar Bintaro sector 2, pasar Serpong berada pada kuadran I, yaitu merupakan keadaan yang menguntungkan. Stategi yang harus di terapkan ialah strategi agresif, supaya bisa menyaingi pasar modern.

\section{E. KESIMPULAN}

Alasan utama perlunya peremajaan ialah ketatnya kompetisi yang terjadi pada pasar. Pasar tradisional di kota Tangerang Selatan belum melakukan peremajaan secara sepenuhnya, yaitu perencanaa fisik serta peningkatan non fisiknya untuk lebih bersih, rapi serta nyaman yang tujuan akhirnya menarik minat halayak. Hasil analisis SWOT di peroleh keempat pasar tradisional ini ada di kuadran I. ini karena keempat pasar punya peluang serta kekuatan cukup kuat. Maka jika pasar di kembangkan akan sangat baik. 


\section{DAFTAR PUSTAKA}

Lukito, Y. N. (2018). Revitalisasi Ruang Pasar Tradisional Melalui Pendekatan Desain dan Interaksi Pengguna Ruang. Yogyakarta: Deepublish (grup penerbitan CV BUDI UTAMA).

Malano, H. (2011). Selamatkan Pasar Tradisional. Jakarta: PT Gramedia Pustaka.

Suartha, N. (2016). Revitalisasi Pasar Tradisional Bali Berbasis Pelanggan ( Studi Kasus di Kabupaten Gianyar). Jakarta: Rajagrafindo persada.

Sugiyono. (2012). Kuantitatif Kualitatif dan R\&D. Bandung: Alfabeta.

Sugiyono. (2014). Penelitian Pendidikan Pendekatan Kuantitatif, kualitatif Dan R\&D. Bandung: Alfabeta.

Sugiyono. (2016). Metode Penelitian kuantitatif Kualitatif dan Kombinasi (Mixed Methods). Bandung: Alfabeta.

Al Masitoh, E. (2013). Upaya Menjaga Eksistens Pasar Tradisional:Studi Revitalisasi Pasar Piyungan . Bantul: Jurnal PMI.

alfianita, E., \& Andy, f. (n.d.). Revitalisasi Pasar Tradisional dalam Good Governance (Studi di pasar tumpeng Kab.Malang). Jurnal Administrasi Publik (JAP), 3(5), 758-762.

Anggraini, G., Amalia, D., Hermawan, F., \& Ismiyati. (2016). Standar Revitalisasi Pasar Tradisiona; Di Indonesia (studi Kasus Pasar Traisional Di Kota Semarang). Jurnal Karya Teknik Sipil, 5 (2), 211-219.

ArRosyidi, H. M. (2016). Analisis Implementasi Revitalisasi PT IR Soekarno KAb.Sukoharja Dalam Rangka Meningkatkan kualitas Pelayanan. Universitas Diponegoro Semarang.

Caroline. (2011). Studi Kelayakan Pasar Ngalihan Kota Semarang. Semarang: Jurnal Dinamika Manajemen 2(2).

Dewar, D., \& D, V. (2007). Perubahan fungsi koridor jalan suryono akibat keberadaan Pasar Bulu Semarang. Semarang.

Dwi, U. (n.d.). Pengembangan Pasar Tradisional Menghadapi Gempuran Pasar Modern di Kota Yogyakarta. Semarang: Proceeding Simposium Nasional ASIAN III,Universitas 17 Agustus 1945.

Ekomadyo, S, A., \& Hildayatsyah, S. (2013). Isu,Tujuan, dan Kriteria Perancangan Pasar Tradisional, (Temu IImiah IPLBI).

Fanani, F., \& Fitrotun, N. (2013). Manajemen Strategi Pengelolaan Ketertiban Pedagang di pasar Tradisional Jagir Surabaya. (http:/ejournal.unesa.ac.id).

G, Q. C. (2014). Model Penataan Pasar Tradisional Berdasarkan Karakteristik Kegiatan. Fasilitas dan Utilitas, Studi Kasus Pasar Tanjung di KAbupaten Jember (http://repository.unej.ac.id).

Genah, T., \& JL, K. (2013). Redesain Pasar Tradisional Bersehati di MAnado . http://ejournal .unesa.ac.id. 
Lesmana, R., \& Ayu, S. D. (2019). Pengaruh Kualitas Produk Dan Citra Merek Terhadap Keputusan Pembelian Kosmetik Wardah PT Paragon Tehnology And Innovation. Jurnal Pemasaran Kompetitif, 2(3), 59-72.

Lesmana, R., Habiyah, W., \& Nabila, N. I. (2020). Peran Kepuasan Wisatawan Terhadap Loyalitas Wisatawan Pada Objek Wisata Kepulauan Seribu Jakarta. JIMF (Jurnal IImiah Manajemen Forkamma), 3(2).

Lesmana, R., Widodo, A. S., \& Sunardi, N. (2020). The Formation of Customer Loyalty From Brand Awareness and Perceived Quality through Brand Equity of Xiaomi Smartphone Users in South Tangerang. Jurnal Pemasaran Kompetitif, 4(1), 1-12.

Nugroho, Asa, B. A., \& Nurcahyanto, H. (2014). Strategi Pengembangan Pasar Tradisional di Kota Jakarta. Jurnal Fakultas IImu Sosial dan IImu Politik Universitas Diponegoro:3(http://download.portalgaruda.org.

Rufaidah, P. (2008). Peran Teknologi Komunikasi Dalam Rantai Nilai Pedagang di Pasar Tradisional. Sosioteknologi Edisi 14, 7, 405-408. Retrieved from http://download.portalgaruda.org

Susanti, F. (2019). Peran Satuan Polisi Pamong Praja Dalam Penatan Pedagang Kaki Lima studi kasus pada Pasar Serpong ( Kecamatan Serpong). Jurnal IImiah Manajemen Forkamma 2(1), Unpam Press, 2(2), 1-17. doi:DOI: 10.32493/frkm.v2i2.3402

Susanti, F., \& Novia. (2019). Peran Satuan Polisi Pamong Praja Dalam Penataan Pedagang Kaki Lima studi kasus pada Kota Tangerang Selatan. Inovasi Jurnal IImiah IImu Manajemen, 6(2), 59-68. doi:DOI: http://dx.doi.org/10.32493/Inovasi.v6i2.p59-68.3679

Sunardi, N., \& Lesmana, R. (2020). Pelaksanaan Alokasi Dana Desa Terhadap Manajemen Keuangan Desa dalam Meningkatkan Efektivitas Program Desa Sejahtera Mandiri Di Desa Cihambulu, Kec. Pabuaran, Kab. Subang. Jurnal SEKURITAS (Saham, Ekonomi, Keuangan dan Investasi), 3(3), 277-288.

Peraturan Daerah No 9 Tahun 2013 tentang peraturan Pasar Tradisional. (2013).

Undang, U. (2013). Republik Indonesia. Peraturan Menteri Perdagangan RI No 70 Tahun 2013 tentang Pedoman Penataan dan Pembinaan Pasar Tradisional, Pusat Perbelanjaan dan Toko Modern. Jakarta: Sekretariat Jenderal Kementerian Perdagangan.

Undang, u. (2015). Republik Indonesia. Standar Nasional Indonesia PAsar Rakyat . Jakarta: Republik Indonesia.

(n.d.). Retrieved 2 8, 2020, from https;//sleekr.co/blog/analisis-swot-untuk-bisnis-umkm/.

(n.d.). Retrieved 2 8, 2020, from https://ryuzakifaiz.blogspot.com/2013/12/analisis-swotkekuatan-kelemahan.html.

(2020, 2 8). Retrieved from https;//muamala.net/teoti-analisis-swot/.

$(2020,28)$.Retrieved from https;//makalahperencanaanpembelajaran.blogspot.com/2011 /05/analisis-pasar-tradisional-ditengah.html.

(2020, 2 8). Retrieved from https://makalah-smp-sma-lkp.blogspot.com/2013/07/analisisaksibilitas-konsumen-pada-html. 